consulted me. Forty-two days had passed since the complaint started, even then the consistence of the penis was harder than that of cartilage. There was no trouble with regard to micturition, but he complained of local pain. The dorsal vein of the penis was prominent. I was at first tempted to make multiple inctsions as recommended by Romanis and Mitchiner, but later thought of trying the effect of leeches once again. Six leeches of moderate size were distributed one on either side of the body of the penis near the glans, two on the dorsum and the remaining two at the root of the penis. The effect was quite marked, as the leeches sucked in blood the penis became gradually smaller and softer. There was slight oozing for a day, but the bite marks healed up afterwards. So far, there has been no recurrence of the trouble.

Interesting points about the case.

1. Absence of any abnormality even after $x$-ray examination.

2. No history of sexual excesses or unnatural offences.

3. Persistence of the condition for a period of six weeks without relief.

4. Maximum doses of potassium bromide had no effect on the condition.

Thus two important causes of priapism, viz, sexual excesses and malpractices and the presence of spinal tumours appear to be eliminated in this case. The condition was evidently due to local congestion and two leeches were not enough to relieve it.

\section{SUSPENDED ANIMATION}

By A. F. W. DA COSTA, F.R.c.s.e., D.T.M., L.M.S., v.D.

Civil Surgeon, Buldana

CASES are on record where it is alleged that persons who have been taken as dead have recovered when about to be buried; also bodies of others which have been exhumed a few days after burial have been found to be in a state of contortion, clearly testifying to a struggle for breath or life. We also hear of persons being in a state of trance, in which breathing or heart beats are scarcely or not perceptible.

The usual signs of death are : stoppage of breathing, cessation of heart beat, lowering of the body temperature, loss of the corneal and pupillary sensibility, and so on.

I recently saw an Indian who could expand his chest thirteen inches, and had perfect control over his heart and blood vessels. $\mathrm{He}$ could completely stop his radial, carotid or temporal pulses either singly or simultaneously on both sides for several seconds at a time; he could also stop his heart beats for several seconds and I could not discover with the aid of a phonendoscope even the suspicion of a heart sound, thus showing perfect control over his circulatory system.

There is on record the case of Colonel Townshend who used to say that he could die and come to life again, as he wished. He used to lie flat on his back and his radial pulse gradually sank till it was imperceptible, his heart became still and his breath used to stop until it did not dim the shining mirror held to his mouth. After a period of several minutes he used to breathe gently and slowly restore himself to animation again.

In the East one comes across Sadhus living chiefly in the jungles and in the mountains, who practise 'Yoga' and who appear to have perfect control over the various systems.

\section{A CASE OF ECLAMPSIA}

Treated with 'Chloral Hydras'

\section{By L. R. LAKHKAR \\ CAPTAIN, A.I.R.o.}

Chief Medical Officer, Kawardha, Kawardha State (E. S. A.)

ON the morning of 3rd April, 1935, I was called in to see a case of delayed labour accompanied by fits. The patient was a young girl, 18 years old and of a good constitution.

Previous history.-Patient's mother died of a similar trouble during delivery. The patient had one abortion two years back.

Present history.-The patient noticed swelling of both feet and legs 15 days previously. On the afternoon of the 2nd April she had pain in the abdomen. It was intermittent and thought to be labour pain. The pain continued for some hours and then disappeared. At 1 p.m. in the night she suddenly vomited and rolled her eyes upwards, her whole body became rigid and began to shake. This continued for 15 minutes. She had three similar attacks before morning. On examination at 7 a.m. on the morning of the 3rd her temperature was $97.8^{\circ} \mathrm{F}$.; pulse rate 82 per minute. There was no pain in the abdomen, but the child was alive as fotal heart sounds could be heard. Her legs and feet were swollen and the swelling pitted on pressure. She was made to pass some urine, which on examination was found to be loaded with albumin. A diagnosis of eclampsia was made and treatment started.

Treatment.-An injection of $1 / 3 \mathrm{gr}$. morphia was given and $500 \mathrm{c.cm}$. of blood removed from the right arm by venesection. One hour later, 40 grs. of chloral hydras were given by mouth dissolved in $100 \mathrm{c.cm}$. of water. The patient had three fits after this. Another injection was given 3 hours after followed by chloral hydras. Chloral hydras was repeated six. twelve and eighteen hours after the first injection. The patient passed no urine during the whole day consequently it was removed by catheter at 8 p.m. The whole genitalia had swollen enormously. At 9 p.m. pains again started and at midnight the patient was delivered of a male child which lived only ten minutes. Surgical asepsis was rigidly observed during the delivery. The patient had no fits after the second dose of chloral. She was given a diuretic mixture next day and castor oil in the night. On the morning of the 5 th she had three motions. During the treatment the patient was kept on plenty of milk and water. The urine was free of albumin on the morning of the 4 th. The patient subsequently made an uneventful recovery.

\section{CORRIGENDUM}

IN Lieutenant-Colonel A. N. Palit's paper on 'Splenectomy for Tropical Splenomegaly' which appeared in our May issue, on p. 244, first column, thirteenth line from the top, the words 'this was one of the patients that died subsequently' should read ' was one of these patients that died subsequently'. 